trained. I shared his opinion then, and still do.

It is common knowledge that many patients, who, on doctors' orders, have received months of heat, traction, massage, and exercises from a physiotherapist for a painful neck or back, eventually go off on their own and are put right by a treatment or two from a lay manipulator. Is there any good reason why these simple manoeuvres should not have been carried out at a doctor's request by the physiotherapist?

However, the other asnect of the question must be considered. The effectiveness of the phvsiotheranist also denends on doctors not sending along unsuitable cases. For examole, they should no longer send patients along with a "frozen shoulder" for vain nhvsiotherapy, when a few intraarticular injections of hydrocortisone provide the effective treatment.

The coin has two sides. There would, in my opinion, be plenty enough phvsiotherapists to go round if on the one hand they were sent only such cases as were likely to respond, and on the other they were taught as students a direct manual approach to all suitable lesions.-I am, etc.,

\section{James Cyriax.}

\section{London W.1.}

\section{REFERENCE}

1 Watson-Jones, Sir R., The Times, 10 July, 1962, p. 11 .

\section{Seebohm Sequel}

SIR,-I have much svmpathy for Dr. G. W. Roberts's concern (28 November, p. 561) over the implementation of the Local Authority Social Service Act. Your leading article should now read "Seebohm Seauelae" for the proposed Misuse of Drugs Bill would replace the Advisory Committee on Drug Addiction with an advisory council which will include one medical practitioner, one dental surgeon. one veterinary surgeon, and one pharmacist as well as somehody elce identified with the drug industry, and 14 people with recent and extensive experience of the social aspects of drug addiction. The Bill is primarily concerned with prescribing of drugs of addiction and the treatment and rehabilitation of addicts, which would appear to me to be medical matters.

Once upon a time there were few social workers, but now they have proliferated to such an extent that they are usurping the role of the doctor at all levels. If it were shown that they had the necessary skills and were effective in their allotted tasks one would have to concede that for the sake of progress these changes must be. But there is not a shred of evidence that this is so. Our universities and colleges have been churning out social workers for many years now, and departments of social science compare in size with those of science, engineering, and medicine, but apart from spearheading the attack on our culture and its values they have made precious little impact on the problems of our society; indeed we are faced with a rapid increase rather than a reduction in crime, divorce, illegitimacy, abortion, drug addiction, battered babies, parental and child neglect, and whatever else you may care to mention.
Most social workers are intelligent and educated, but these qualities do not in themselves guarantee that they are effective in their work-which is not entirely surprising for neither have those who teach them shown such competence. Their roles may be defined, but they have not yet been established, and one would have though before increasing the size of our social services, providing career structures, and giving social workers authority over doctors, one would have investigated what they are capable of doing and what it costs and compared cost and efficiency with alternative methods.

A year ago I decided to experiment and took on two trained nurses who were health visitors in a neighbouring borough. After three months' attendance at our inpatient and day hospital units with a planned course of instruction, they were more competent in dealing with material degrees of psychiatric disability in the community than a recently qualified psychiatric social worker, even though their educational attainments were less. Of even greater importance, they could effectively carry a larger case load

Seebohm has reinforced a trend which is most questionable, especially as social services now come under one Ministry and their cost will encroach on the financing of the Health Service. It occurs to me that the time is adoropriate for a bit of cost accounting. I realize that we in psychiatry are also vulnerable and it may need the Auditorgeneral to put our own house in order. On the debit side should go the prominent part some psychiatrists have played in encouraging the present trend.-I am, etc.,

\section{Queen Elizabeth Hospital, \\ Birmingham.}

MYRE SIM.

\section{Endocrine Function in Homosexuals}

SIR,-We have read with interest the communication from Dr. J. A. Loraine and others (14 November, p. 406), but we would question the interpretation of the data on which they base their conclusion that there is a significant endocrine abnormality in homosexuals.

The testosterone and epitestosterone excretion in the three male subjects is compared with that found in a group of normal heterosexual males. Reference to the paper by Cooper et al..$^{1}$ shows that this normal group consisted of 14 subjects in whom the testosterone values ranged from 35.4-147.4 $\mu \mathrm{g} . / 24$ hours and the epitestosterone values from $4.7-52.4 \mu \mathrm{g} . / 24$ hours. The mean values for the individual male homosexuals (testosterone, 39.6, 48.2, and $56.7 \mu \mathrm{g} . / 24$ hours; epitestosterone, 13.6, 16.1, and 24.7 $\mu \mathrm{g} . / 24$ hours) all fell within these ranges. It is not clear from either paper how the mean values of $73 \pm 34.3 \mu \mathrm{g} . / 24$ hours for testosterone and $35.4 \pm 19.7 \mu \mathrm{g} . / 24$ hours for epitestosterone were calculated for the normal group, and it is also therefore difficult to understand how the highly significant differences of each individual from the group mean were derived and thereafter to assess the validity of these findings. A similar argument can be advanced about the data presented on the female subjects.

We should also have appreciated rather more extensive clinical data on the female homosexuals, in view of the menstrual irregularity in three of these women in one of whom a tentative diagnosis of the SteinLeventhal syndrome had been made. Since it has been reported ${ }^{2}$ that the plasma testosterone is high in this syndrome, the finding of a high urinary testosterone excretion in Subject 4 may well be a reflection of this clinical situation.

In the past, it has been stated that endocrine factors play no part in the causation of homosexuality, ${ }^{3}$ but recent developments have reopened this field of inquiry. More elegant and sensitive assav techniques in endocrinology are now available, in part owing to the important contribution of $\mathrm{Dr}$. Loraine and his group. Recently, too, there has been a series of reports based mainly on animal work of the importance of endocrine factors particularly at critical phases of development in the moulding of sexual behaviour and orientation..$^{4-6}$ It is to be welcomed that the Edinburgh group are working in this field, but we cannot accept that the results so far presented show that there is any important endocrine difference between homosexuals and normal subjects. We are, etc.,

\section{Christine G. Ryrie.} J. Christie Brown.

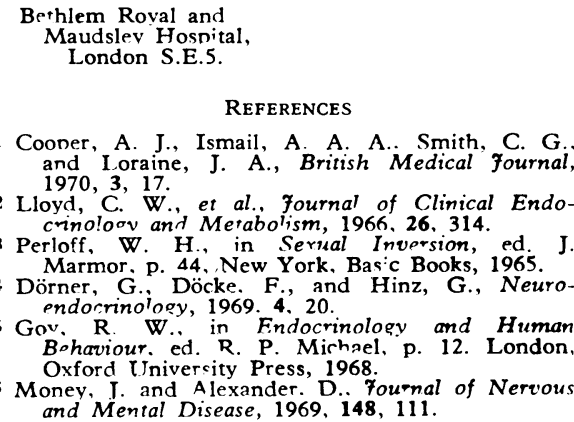

\section{Living it up with Concorde}

SIR-Your correspondents R. T. W. L Conroy (14 November, p. 434) and others (3 October, p. 53) would find a great deal of evidence available to substantiate Sauadron Leader A. N. Nicholson and Dr. F. S. Preston's remarks (24 October, p. 242) if they went along to any aviation medicine library and looked at the manv recent papers written on the subject and the results of symposia held on flight crew rest activity cycles.

Large scale experiments have been going on for the vast few vears to study the subject extensively, and Dr. Nicholson and Dr. Precton have been involved very deeply in such work. A lot is already known on the extent and importance of the disturbances encountered.-I am, etc.

$$
\text { I. C. PERry. }
$$

\section{Denartment of Aviation Medicine,}

H.O. Army Aviation,
Stockbridge, Hants.

\section{Continuous Ventilation and Oedema}

SIR,-A girl aged 4 years with a history of haematemasis and melaena was admitted to the paediatric intensive care unit because she had aspirated blood and gastric contents. After a short interval she developed cyanosis, dyspnoea, bronchospasm, and tachycardia. Ronchi and rales were heard 